Article

Subscriber access provided by King Abdullah University of Science and Technology Library

\title{
Enhanced kinetics of hole transfer and electrocatalysis during photocatalytic oxygen evolution by cocatalyst tuning
}

Ela Nurlaela, Hai Wang, Tatsuya Shinagawa, Sean Flanagan, Samy Ould-Chikh, Muhammad Qureshi, Zoltan Mics, Philippe Sautet, Tangui Le Bahers, Enrique Canovas, Mischa Bonn, and Kazuhiro Takanabe ACS Catal., Just Accepted Manuscript • DOI: 10.1021/acscatal.6b00508 • Publication Date (Web): 23 May 2016

Downloaded from http://pubs.acs.org on May 29, 2016

\section{Just Accepted}

"Just Accepted" manuscripts have been peer-reviewed and accepted for publication. They are posted online prior to technical editing, formatting for publication and author proofing. The American Chemical Society provides "Just Accepted" as a free service to the research community to expedite the dissemination of scientific material as soon as possible after acceptance. "Just Accepted" manuscripts appear in full in PDF format accompanied by an HTML abstract. "Just Accepted" manuscripts have been fully peer reviewed, but should not be considered the official version of record. They are accessible to all readers and citable by the Digital Object Identifier (DOI®). "Just Accepted" is an optional service offered to authors. Therefore, the "Just Accepted" Web site may not include all articles that will be published in the journal. After a manuscript is technically edited and formatted, it will be removed from the "Just Accepted" Web site and published as an ASAP article. Note that technical editing may introduce minor changes to the manuscript text and/or graphics which could affect content, and all legal disclaimers and ethical guidelines that apply to the journal pertain. ACS cannot be held responsible for errors or consequences arising from the use of information contained in these "Just Accepted" manuscripts. 


\title{
Enhanced kinetics of hole transfer and electrocatalysis during pho- tocatalytic oxygen evolution by cocatalyst tuning
}

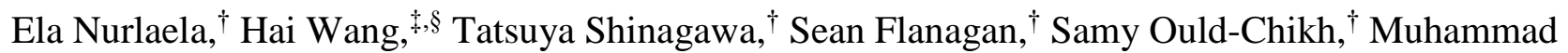 \\ Qureshi, ${ }^{\dagger}$ Zoltán Mics, ${ }^{\dagger}$ Philippe Sautet, , Tangui Le Bahers,, Enrique Cánovas, ${ }^{\ddagger}$ Mischa Bonn, ${ }^{\dagger}$ and \\ Kazuhiro Takanabe*, ${ }^{*}$
}
'Division of Physical Sciences and Engineering, KAUST Catalysis Center (KCC), King Abdullah University of Science and Technology (KAUST), 4700 KAUST, Thuwal, 23955-6900, Saudi Arabia.
Department of Molecular Spectroscopy, Max Planck Institute for Polymer Research, Ackermannweg 10, 55128 Mainz, Ger- many.
${ }^{\S}$ Graduate School of Material Science in Mainz, University of Mainz, Staudingerweg 9, 55128 Mainz, Germany.
"Université de Lyon, Université Claude Bernard Lyon 1, ENS Lyon, Centre Nationale de Recherche Scientifique, 46 allée d'Italie, 69007 Lyon Cedex 07, France.

\begin{abstract}
Understanding photophysical and electrocatalytic processes during photocatalysis in a powder suspension system is crucial for developing efficient solar energy conversion systems. We report a substantial enhancement by a factor of 3 in photocatalytic efficiency for the oxygen evolution reaction (OER) by adding trace amounts ( $\sim 0.05 \mathrm{wt} \%)$ of noble metals (Rh or Ru) to a $2 \mathrm{wt} \%$ cobalt oxide-modified $\mathrm{Ta}_{3} \mathrm{~N}_{5}$ photocatalyst particulate. The optimized system exhibited high quantum efficiencies (QEs) of up to 28 and $8.4 \%$ at 500 and $600 \mathrm{~nm}$ in $0.1 \mathrm{M} \mathrm{Na}_{2} \mathrm{~S}_{2} \mathrm{O}_{8}$ at $\mathrm{pH} 14$. By isolating the electrochemical components to generate doped cobalt oxide electrodes, the electrocatalytic activity of cobalt oxide when doped with $\mathrm{Ru}$ or $\mathrm{Rh}$ was improved compared with cobalt oxide, as evidenced by the onset shift for electrochemical OER. Density functional theory (DFT) calculation shows that the effects of a second metal addition perturbs the electronic structure and redox properties in such a way that both hole transfer kinetics and electrocatalytic rates improve. Time resolved terahertz spectroscopy (TRTS) measurement provides evidence of long-lived electron populations (>1 ns; with mobilities $\mu_{\mathrm{e}} \sim 0.1-3 \mathrm{~cm}^{2} \mathrm{~V}^{-1} \mathrm{~s}^{-1}$ ), which are not perturbed by the addition of $\mathrm{CoO}_{\mathrm{x}}$-related phases. Furthermore, we find that $\mathrm{Ta}_{3} \mathrm{~N}_{5}$ phases alone suffer ultrafast hole trapping (within $10 \mathrm{ps}$ ); the $\mathrm{CoO}_{\mathrm{x}}$ and $M-\mathrm{CoO}_{\mathrm{x}}$ decorations most likely induce a kinetic competition between hole transfer toward the $\mathrm{CoO}_{x}$-related phases and trapping in the $\mathrm{Ta}_{3} \mathrm{~N}_{5}$ phase, which is consistent with the improved OER rates. The present work not only provides a novel way to improve electrocatalytic and photocatalytic performance but also gives additional tools and insight to understand the characteristics of photocatalysts that can be used in a suspension system.
\end{abstract}

\section{KEYWORDS. Photocatalysis, Oxygen evolution reaction, Electrocatalysis, Time-resolved terahertz spectroscopy, Hole transfer kinetics, Tantalum nitride}

\section{Introduction}

Direct conversion of solar energy to chemicals, particularly via photocatalytic water splitting to generate renewable hydrogen, has been a subject of research for decades..$^{1-6}$ The main challenge lies in identifying materials suitable for efficient photocatalysis, i.e., with an optical response in the visible light region, and energy levels compatible with chemical reduction and/or oxidation. These properties converge in $\mathrm{Ta}_{3} \mathrm{~N}_{5},{ }^{1-18}$ which can theoretically achieve a solar to hydrogen efficiency of approximately $17 \%$ using a single semiconductor; nevertheless, non-biased, overall efficient water splitting using this material has not been achieved. ${ }^{1-21}$ For efficient photocatalysis with the powder semiconductor, a solid-electrolyte interface is effectively utilized for charge separation, therein directly inducing surface chemical redox reactions. One strategy to improve the photocatalytic activity of $\mathrm{Ta}_{3} \mathrm{~N}_{5}$ is to decorate the surface with an oxygen evolution reaction (OER) electrocatalyst, being an essential component to achieve high efficiency. ${ }^{21-24}$ Previous work has demonstrated that the photocatalytic OER efficiency can be improved by one order of magnitude by the addition of $\mathrm{CoO}_{x}$ cocatalyst on the $\mathrm{Ta}_{3} \mathrm{~N}_{5}$ surface; when appropriate, heat treatment is applied to construct an intimate $\mathrm{CoO}_{\mathrm{x}}-\mathrm{Ta}_{3} \mathrm{~N}_{5}$ interface. ${ }^{22}$ Generally, the role of the catalyst, which is commonly called a cocatalyst, on the semiconductor surface has been discussed as two-fold: 1) it improves the electrochemical performance by lowering overpotentials for the redox reactions (and resultant electron/hole consumption) and 2) effectively separates the excited charges by using a photocatalyst (semiconductor)-catalyst interface, exploiting the differences in Fermi levels between them. ${ }^{25-29}$

The materials with high rates in electrochemical reactions are naturally considered to be good cocatalysts because fast redox kinetics is strongly correlated with fast carrier consumptions, thus avoiding its recombination. In other words, for slow redox kinetics, deleterious charge recombination is expected. In previous works on electrocatalytic $\mathrm{OER}, \mathrm{CoO}_{\mathrm{x}}$ has been considered 
to be an effective catalyst. ${ }^{30-32}$ Recently, the combination of $\mathrm{CoO}_{\mathrm{x}}$ and a noble metal $\left(M-\mathrm{CoO}_{\mathrm{x}}\right)$, such as an $\mathrm{Au}-\mathrm{CoO}_{\mathrm{x}}$ electrode, has drastically improved its performance, compared with that of its mono-metallic counterpart. ${ }^{30}$ Because of its electronegativity, Au may serve as an electron sink, facilitating the oxidation of $\mathrm{Co}^{\mathrm{II}}$ and $\mathrm{Co}^{\mathrm{III}}$ to $\mathrm{Co}^{\mathrm{IV}}$ and increasing the availability of the active sites for OER. ${ }^{30}$ In situ Raman spectroscopy during the electrochemical OER supports this scenario; it has been demonstrated that the population of $\mathrm{Co}^{\mathrm{IV}}$ states is promoted in the presence of $\mathrm{Au}$, which explains the higher current density on the $\mathrm{Au}-\mathrm{CoO}_{\mathrm{x}}$ sample. ${ }^{30}$ Furthermore, a very recent work by Tae et al. strongly suggest that $\mathrm{CoO}_{\mathrm{x}}$ redox potential was effectively perturbed by $\mathrm{IrO}_{x}$, as inferred from operando X-ray absorption spectroscopy, giving one of the lowest overpotentials of OER ever reported $\left(\sim 0.19 \mathrm{~V}\right.$ at $\left.10 \mathrm{~mA} \mathrm{~cm}^{-2}\right) .{ }^{33}$ Other noble metals, such as $\mathrm{Rh}, \mathrm{Pt}, \mathrm{Ru}, \mathrm{Pd}$, and Ir, were also shown to have a similar impact, suggesting a common underlying mechanism governing the improved performance of $M$-CoOx in OER efficiency. ${ }^{30-32}$

The second role of the cocatalyst is presumed to be the charge separation at the metal (oxide)-semiconductor interface. In fact, in photoelectrochemical OER using a $\mathrm{CoO}_{x} / \mathrm{BaTaO}_{2} \mathrm{~N}$ system, the addition of $\mathrm{RhO}_{\mathrm{x}}$ has been found to significantly improve the photocurrent and lower the onset potential. ${ }^{34}$ It was speculated that there is a synergetic effect between $\mathrm{RhO}_{\mathrm{x}}$ and $\mathrm{CoO}_{\mathrm{x}}$, where $\mathrm{Rh}$ (i.e., in the form of $\mathrm{RhO}_{\mathrm{x}}$ ) forms highly oxidized $\mathrm{Rh}^{4+}$, which promotes effective hole extraction from the bulk Ba$\mathrm{TaO}_{2} \mathrm{~N}$. ${ }^{34}$ To investigate the charge separation on the catalystsemiconductor interface, time-resolved spectroscopy has often been used. Transient absorption spectroscopy (TAS) at the microsecond to second time scale, with low excitation densities on $\mathrm{Fe}_{2} \mathrm{O}_{3}$ and $\mathrm{TiO}_{2}$ photoanodes, revealed an increase in photogenerated holes' lifetime when adding a cocatalyst. ${ }^{35-37}$

In this work, we present a comprehensive study regarding the nature of enhanced photocatalytic OER on Ru and Rh co-loaded $\mathrm{CoO}_{\mathrm{x}} / \mathrm{Ta}_{3} \mathrm{~N}_{5}$ particulate. The electrocatalytic activity of $M$ doped-cobalt oxide $\left(M / \mathrm{CoO}_{\mathrm{x}}\right)$ is interrogated by isolating the electrochemical components to generate doped cobalt oxide electrodes. When doped with $\mathrm{Rh}$ or $\mathrm{Ru}$, the electrocatalytic activity of cobalt oxide is significantly improved, as evidenced by the onset potential. Time resolved terahertz spectroscopy (TRTS) measurement provides evidence of long-lived electron populations (>1 ns; with mobilities $\mu_{\mathrm{e}} \sim 0.1-3 \mathrm{~cm}^{2} \mathrm{~V}^{-1} \mathrm{~s}^{-1}$ ), which are not perturbed by adding $\mathrm{CoO}_{\mathrm{x}}$-related phases. Furthermore, we find that $\mathrm{Ta}_{3} \mathrm{~N}_{5}$ phases alone suffer ultrafast hole trapping (within $10 \mathrm{ps}$ ); the $\mathrm{CoO}_{\mathrm{x}}$ and $M / \mathrm{CoO}_{\mathrm{x}}$ decorations most likely cause a kinetic competition between hole transfer toward the $\mathrm{CoO}_{\mathrm{x}}$-related phases and trapping at the $\mathrm{Ta}_{3} \mathrm{~N}_{5}$ phase (which could be linked with the observed OER improvement). We conclude that the origin of improved photocatalytic OER of $\mathrm{CoO}_{x}$ by doping is two-fold: improved hole transfer kinetics from the semiconductor $\left(\mathrm{Ta}_{3} \mathrm{~N}_{5}\right)$ to doped $\mathrm{CoO}_{\mathrm{x}}$ and improved electrocatalytic performance. Both improvements are associated with work function tuning, as shown by the density functional theory (DFT) calculations.

\section{Experimental and theoretical methods}

\section{Photocatalyst synthesis}

$\mathrm{Ta}_{3} \mathrm{~N}_{5}$ particles were prepared from commercially available crystalline $\mathrm{Ta}_{2} \mathrm{O}_{5}(\geq 99.99 \%$ metal basis, $<5$ microns, SigmaAldrich) by applying direct $\mathrm{NH}_{3}$ nitridation under high temperature, as reported elsewhere. ${ }^{7,22-24}$ In a typical experiment, a total of $0.5 \mathrm{~g} \mathrm{Ta}_{2} \mathrm{O}_{5}$ was wrapped with quartz wool and placed into a tube furnace. The tube furnace was initially purged with $\mathrm{N}_{2}$ before the introduction of $\mathrm{NH}_{3}$ flow at room temperature. The nitridation was conducted at $900{ }^{\circ} \mathrm{C}$, with a heating rate of $5^{\circ} \mathrm{C}$ $\min ^{-1}$ and was held at this temperature for $15 \mathrm{~h}$ under an $\mathrm{NH}_{3}$ flow of $200 \mathrm{~mL} \mathrm{~min}^{-1}$. The sample was allowed to cool to room temperature inside a tube furnace under $\mathrm{NH}_{3}$ flow. Cobalt deposition onto the $\mathrm{Ta}_{3} \mathrm{~N}_{5}$ was conducted using the wet-impregnation method. ${ }^{22,23}$ A known amount of $\mathrm{Co}\left(\mathrm{NO}_{3}\right)_{2} \cdot 6 \mathrm{H}_{2} \mathrm{O}$ (Aldrich, $99 \%$ ) and $0.1 \mathrm{~g} \mathrm{Ta}_{3} \mathrm{~N}_{5}$ were suspended in $5 \mathrm{~mL} \mathrm{H}_{2} \mathrm{O}$ and sonicated for 5 minutes. The suspension was then subjected to evaporation to remove water under a slight vacuum at 70 mbar for 30 minutes, followed by 50 mbar for 30 minutes. Subsequently, the resulting powder was subjected to heat treatment at $700{ }^{\circ} \mathrm{C}$ for $1 \mathrm{~h}$ under $200 \mathrm{~mL} \mathrm{~min}^{-1} \mathrm{NH}_{3}$ flow. In a similar manner, the cooling process inside the tubular furnace was conducted under $\mathrm{NH}_{3}$ flow. A noble metal cocatalyst ( $\mathrm{Rh}$ or $\mathrm{Ru}$ ) was subsequently deposited onto the Co-impregnated $\mathrm{Ta}_{3} \mathrm{~N}_{5}$ (hereafter, $\mathrm{CoO}_{\mathrm{x}} / \mathrm{Ta}_{3} \mathrm{~N}_{5}$ ) by applying a similar method of wet impregnation, with or without subsequent reduction at $400{ }^{\circ} \mathrm{C}$ for $1 \mathrm{~h}$ under a $\mathrm{H}_{2}$ flow. The chemicals used for noble metal precursors were $\mathrm{Na}_{3} \mathrm{RhCl}_{6} \cdot 6 \mathrm{H}_{2} \mathrm{O}$ and $\mathrm{RuCl}_{3} \cdot \mathrm{xH}_{2} \mathrm{O}$ and were of analytical grade (Aldrich, $99.99 \%$ trace metal basis). For TRTS measurements, $\mathrm{SiO}_{2}$ supported $M / \mathrm{CoO}_{\mathrm{x}}$ samples were prepared in an identical procedure. Nonporous spherical $\mathrm{SiO}_{2}$ (COSMO 30, JGC Catalysts and Chemicals Ltd.) was selected because of similar surface area as $\operatorname{Ta}_{3} \mathrm{~N}_{5}\left(10 \mathrm{~m}^{2} \mathrm{~g}^{-1}\right)$.

The diffuse reflectance spectra, surface oxidation state, and morphology of $\mathrm{CoO}_{\mathrm{x}} / \mathrm{Ta}_{3} \mathrm{~N}_{5}$ and $M-\mathrm{CoO}_{\mathrm{x}} / \mathrm{Ta}_{3} \mathrm{~N}_{5}$ were characterized; the details are presented in Supporting Information (section S1.1).

\section{Photocatalytic reaction}

The photocatalytic reactions were performed in a recirculating batch reactor connected to a gas chromatography (GC) unit equipped with a vacuum line. ${ }^{6,23,24}$ The reactant solution was maintained at room temperature by using a flow of cooling water during the reaction. Before irradiation, the reaction vessel was degassed several times to remove air, followed by the introduction of 100 torr of Ar gas into the photocatalytic system. A Xe lamp (CERMAX PE300-BF, 300-W) was used as a light source, and the irradiation wavelength was controlled with a combination of a cold mirror and a water filter $(350<\lambda<800$ $\mathrm{nm})$. A cut-off filter (HOYA L 42) was used with the aforementioned light source $(420<\lambda<800 \mathrm{~nm})$. The homogeneity of the solution during the reaction was maintained by agitation with a magnetic stirrer. The gases evolved were analyzed by using GC (Bruker 450 GC, TCD, Ar gas, molecular sieve 13X). All the samples were tested for photocatalytic OER using $0.1 \mathrm{M}$ $\mathrm{Na}_{2} \mathrm{~S}_{2} \mathrm{O}_{8}$ as the sacrificial electron acceptor. This strong electron acceptor facilitates the electron consumption process to conduct, in turn, the hole consumption process, i.e., OER, as the kinetically relevant step. (Similar concept to rate determining step (rds): However, the photocatalytic process has parallel reaction pathways (e.g., reduction and oxidation), so this term, i.e., rds, does not apply because it indicates an elementary step that pins the overall rate within sequential elementary reactions.) In a typical experiment, a known amount of $\mathrm{Na}_{2} \mathrm{~S}_{2} \mathrm{O}_{8}$ was dissolved in $100 \mathrm{~mL} \mathrm{H}_{2} \mathrm{O}$ and the $\mathrm{pH}$ was adjusted with a $\mathrm{NaOH}$ solution. Then, a 50-mg sample was suspended in a corresponding solution and sonicated for $5 \mathrm{~min}$.

\section{Electrochemical measurement}


Co was electrochemically deposited onto $\mathrm{Ni}$ foam (NF) of a $1 \mathrm{~cm} \times 1 \mathrm{~cm}$ geometric surface by chronopotentiometry. NF was immersed in a deposition bath containing $0.5 \mathrm{mM}$ cobalt nitrate $\left(\mathrm{Co}\left(\mathrm{NO}_{3}\right)_{2}\right.$, Sigma-Aldrich, $\left.99.999 \%\right)$. A constant current of $-10 \mathrm{~mA}$ was applied for $1 \mathrm{~h}$ at $298 \mathrm{~K}$. Rh and Ru were placed by chronopotentiometry onto the Co supported on NF, a bare NF, a Co plate and a Ni plate. A metal precursor solution contained $0.5 \mathrm{mM}$ of $\mathrm{Rh}$ (hexachlororhodate, Sigma-Aldrich) or Ru (Ruthenium chloride hydrate, Sigma-Aldrich). Constant currents (NF: $-1 \mathrm{~mA}$, others: $-0.3 \mathrm{~mA}$ ) were applied for $1 \mathrm{~h}$. All the electrochemical deposition was carried out in 3-electrode configuration, with a Pt wire and $\mathrm{Hg} / \mathrm{HgSO}_{4}\left(\right.$ sat. $\mathrm{K}_{2} \mathrm{SO}_{4}$ ) as counter and reference electrodes, respectively. Anodic polarization over the prepared electrodes was performed at $298 \mathrm{~K}$ with a scan rate of $-1 \mathrm{mV} \mathrm{s}^{-1}$ using a research-grade potentiostat system (VMP3) purchased from BioLogic Science Instruments. For all measurements, a Pt wire and $\mathrm{Hg} / \mathrm{HgO}$ (sat. $1 \mathrm{M} \mathrm{NaOH}$ ) were used as counter and reference electrodes, respectively. Solution resistances were measured by impedance spectroscopy performed at $100 \mathrm{kHz}$ with $10 \mathrm{mV}$ amplitude at $298 \mathrm{~K}$.

Time-resolved $\mathrm{THz}$ spectroscopy

We used optical pump-THz probe spectroscopy to investigate the charge carrier dynamics on $M / \mathrm{CoO}_{\mathrm{x}} / \mathrm{Ta}_{3} \mathrm{~N}_{5}$ nanocomposites. In these types of measurements, the nanocomposite is photoexcited by an ultrashort ( $100 \mathrm{fs}$ ) laser pulse at wavelengths of $400 \mathrm{~nm}$ and $800 \mathrm{~nm}$. Subsequently, a freely propagating $\mathrm{THz}$ pulse interrogates the conductivity of the generated free charge carriers in the frequency range $0.4-2 \mathrm{THz}$ (2-8 $\mathrm{meV})$. The evolution of the carrier conductivity is then measured with a time resolution down to $\sim 100 \mathrm{fs}$. The technique, owing to its low probing frequency, resolves the motion of carriers at a $\sim 10 \mathrm{~nm}$ length scale. Consequently, it enables direct monitoring of carrier transport dynamics in nanostructured systems. ${ }^{38}$

Our optical pump-THz probe (OPTP) setup was driven by ultrashort laser pulses with a temporal length $\sim 40 \mathrm{fs,} \mathrm{pulse} \mathrm{energy}$ $\sim 1 \mathrm{~mJ}$, mean wavelength of $800 \mathrm{~nm}$ and repetition rate of $1 \mathrm{kHz}$, generated by a Ti:sapphire amplified laser system (Spitfire ACE by Spectra-Physics). Part of the laser power ( 20\%) was used for $\mathrm{THz}$ generation and detection: $\mathrm{THz}$ pulses were generated via nonlinear mixing in a (110) oriented $1 \mathrm{~mm}$ thick ZnTe crystal. The generated $\mathrm{THz}$ pulses were focused onto the sample using parabolic mirrors. The transmitted $\mathrm{THz}$ pulses were focused onto a sensor consisting of a $1 \mathrm{~mm}$ thick (110) oriented ZnTe crystal. The THz pulses were detected in a phase-sensitive fashion using the electro-optic effect. The larger part of the laser power was used for photoexcitation as is or frequency-doubled by second harmonic generation in a BBO crystal. The size of the photoexcited part of the sample was always much larger than the spot size of the $\mathrm{THz}$ beam on the sample. The pump fluence of the photoexcitation was $50-200 \mu \mathrm{J} \mathrm{cm} \mathrm{cm}^{-2}$ at wavelengths of 400 and $800 \mathrm{~nm}$. During the measurements, the samples were placed into an $\mathrm{N}_{2}$ purged box to avoid any possible photo-oxidation.

\section{Theoretical method}

All theoretical calculations were performed using the Vienna $\mathrm{Ab}$ initio Software Package (VASP) ${ }^{39-41}$, version 5.3.5. DFT was used with the PBE GGA functional. ${ }^{42}$ Cobalt oxides are known to be strongly correlated materials. Even hybrid functionals that are popular for semiconductors fail to reproduce the electronic structure of this family of compounds. ${ }^{43}$ For that reason, the Hubbard Hamiltonian (noted $+\mathrm{U}$ ) was added in the calculations. This approach has proven its reliability for several metal oxides, including cobalt oxides. ${ }^{43-46}$ More precisely, the formalism proposed by Dudarev et al. $^{47}$ was used, along with the following U-J values: $3.5 \mathrm{eV}$ for $\mathrm{Co}, 3.0 \mathrm{eV}$ for $\mathrm{Ru}$ and 3.3 $\mathrm{eV}$ for $\mathrm{Rh}$, based on previous works. ${ }^{47-49}$

The convergence criterion for the SCF cycles was fixed at $10^{-6} \mathrm{eV}$ per unit cell. The $\mathrm{E}_{\text {ncut }}$ value, defining the basis set size, was fixed at $400 \mathrm{eV}$. The $\mathrm{k}$-points sampling was done with a $3 \times 3 \times 1$ Monkhorst-Pack grid for slab calculations and $12 \times 12 \times 12$ grid for the bulk calculation. The core electrons were described by using the projector-augmented plane wave (PAW) approach. The convergence criterion for geometry optimization was 0.01 $\mathrm{eV} \AA^{-1}$ for the forces.

All slabs were $2 \times 2$ supercells of the primitive surface cell. A thickness of five layers (containing five Co planes) was used, based on the work of Bajdich et al. ${ }^{44}$ During the geometry relaxation of the surface, only the atoms were allowed to relax, and the cell parameters were fixed for the ones determined on the bulk $\mathrm{CoOOH}$. Charge analyses were performed using the Bader scheme based on electron density using the software developed by Henkelman et al. ${ }^{50}$ For each system, several spin states were investigated to find the most stable one. The low spin (LS) and high spin (HS) labeling were based on analyses of the magnetic moment projected on atoms.

Bajdich et al. proved that the active phase of cobalt oxide at the potential and $\mathrm{pH}$ of the OER is the $\mathrm{CoOOH}$ phase by using thermodynamic experimental or computed (using DFT) data. ${ }^{44}$ Furthermore, they also showed that two surfaces are stable at the working condition of the OER, namely, the (01-12) O-terminated and the (10-14) OH-terminated surfaces. However, the most active surface is the (10-14) surface, leading to an overpotential for the OER, estimated as half of the one of the (01-12) surface. For these reasons, the calculations were performed on the (10-14) surface of $\mathrm{CoOOH}$. On this surface, the oxidation state of Co is +III (low spin state). The influence of Rh(III) doping was determined by substituting one Co of the surface with $\mathrm{Rh}$. The influence of $\mathrm{Ru}(\mathrm{IV})$ and $\mathrm{Rh}(\mathrm{IV})$ doping was determined by substituting one Co of the surface with $\mathrm{Ru}$ or $\mathrm{Rh}$ and by removing one top $\mathrm{H}$ atom to allow the increase in oxidation state compared with Co. This corresponds to a $25 \%$ substitution of the Co surface atoms. To be consistent within this manuscript, notation of the Co sample is kept to be $\mathrm{CoO}_{\mathrm{x}}$ for DFT calculation section.

The thermodynamic potential necessary to split water molecules, corresponding to the half reaction (1), is $1.23 \mathrm{~V}$ vs. RHE. In practice, a higher potential is always needed to overcome kinetic and thermodynamic barriers. The difference between the real potential and the ideal one is called the overpotential $(\eta)$.

$$
2 \mathrm{H}_{2} \mathrm{O} \rightarrow \mathrm{O}_{2}+4 \mathrm{H}^{+}+4 e^{-}
$$

The overpotential has two origins: kinetic barriers (related to transition state energies) and thermodynamic barriers (related to the stability of the intermediates). For OER on $\mathrm{CoO}_{\mathrm{x}}$, the active sites are believed to be adsorbed $\mathrm{O}, \mathrm{OH}$ and $\mathrm{OOH}$ groups on a surface vacancy (denoted by $*$ ). The following equations resume the elementary steps of the OER:

$$
\begin{aligned}
& \mathrm{H}_{2} \mathrm{O}+* \rightarrow * \mathrm{OH}+\mathrm{H}^{+}+e^{-} \\
& * \mathrm{OH} \rightarrow * \mathrm{O}+\mathrm{H}^{+}+e^{-} \\
& * \mathrm{O}+\mathrm{H}_{2} \mathrm{O} \rightarrow * \mathrm{OOH}+\mathrm{H}^{+}+e^{-} \\
& * \mathrm{OOH} \rightarrow *+\mathrm{O}_{2}+\mathrm{H}^{+}+e^{-}
\end{aligned}
$$


The free energy associated with these steps is defined as:

$$
\begin{aligned}
& \Delta G_{1}=\Delta G_{\mathrm{OH}}-e U-k_{\mathrm{B}} T \log _{10} p H \\
& \Delta G_{2}=\Delta G_{\mathrm{O}}-\Delta G_{\mathrm{OH}}-e U-k_{\mathrm{B}} T \log _{10} p H \\
& \Delta G_{3}=\Delta G_{\mathrm{OOH}}-\Delta G_{\mathrm{O}}-e U-k_{\mathrm{B}} T \log _{10} p H \\
& \Delta G_{4}=4.92-\Delta G_{\mathrm{OOH}}-e U-k_{\mathrm{B}} T \log _{10} p H
\end{aligned}
$$

where $U$ is the potential of the NHE. The sum of the four $\Delta G$ has been set to $4.92 \mathrm{eV}$, that is, the free energy for the formation of two water molecules. This thermodynamic approach avoids the calculation of the $\mathrm{O}_{2}$ bond energy, which is poorly estimated at the DFT-GGA level. A pH variation will shift all the $\Delta G$ s of the same amount without changing the orders. This is the reason why one can work theoretically in acidic $\mathrm{pH}$ while, experimentally, the $\mathrm{pH}$ is basic. A detailed explanation of how these $\Delta G \mathrm{~s}$ are computed is given in Supporting Information (section S4.1).

The free energies of the reactions (6)-(9) allows for estimating the thermodynamics overpotential:

$$
\eta(\mathrm{V})=\frac{\max \left(\Delta G_{i}\right)}{e}-1.23
$$

This computational approach only calculates the thermodynamic overpotential and hence lacks kinetic information. The potential dependence of the free energy is approximated by the computational hydrogen electrode model which gives good results for coupled proton-electron transfers. ${ }^{51}$ The method has been successfully applied for other materials (including $\mathrm{CoOOH}$ compounds) to understand electrocatalytic OER activity. ${ }^{44-46,52}$

\section{Results and discussion}

$\mathrm{CoO}_{\mathrm{x}} / \mathrm{Ta}_{3} \mathrm{~N}_{5}$ particles were synthesized according to the literature. ${ }^{22,23}$ Briefly, $2 \mathrm{wt} \%$ (metallic base) Co-loaded $\mathrm{Ta}_{3} \mathrm{~N}_{5}$ was heat treated at $700{ }^{\circ} \mathrm{C}$ for $1 \mathrm{~h}$ under $\mathrm{NH}_{3}$ flow to generate a reproducible photocatalytic performance. The addition of $M 0.05$ wt $\%$ (metallic base) to $\mathrm{CoO}_{\mathrm{x}} / \mathrm{Ta}_{3} \mathrm{~N}_{5}$ was achieved by immersing metal ions and heating under a $\mathrm{N}_{2}$ or $\mathrm{H}_{2}$ atmosphere at $400{ }^{\circ} \mathrm{C}$. Detailed results for physicochemical characterization are listed in Supporting Information (Figures S1-S4). The photocatalytic activities of bare $\mathrm{Ta}_{3} \mathrm{~N}_{5}, \mathrm{CoO}_{\mathrm{x}} / \mathrm{Ta}_{3} \mathrm{~N}_{5}$, and $M / \mathrm{CoO}_{\mathrm{x}} / \mathrm{Ta}_{3} \mathrm{~N}_{5}$ samples were tested for OER in the presence of $0.1 \mathrm{M} \mathrm{Na}_{2} \mathrm{~S}_{2} \mathrm{O}_{8}$ as the sacrificial electron acceptor. Figure 1A depicts the effects of various modifications on $\mathrm{Ta}_{3} \mathrm{~N}_{5}$ on the photocatalytic OER. In agreement with previous reports, ${ }^{22,23}$ the addition of $\mathrm{CoO}_{\mathrm{x}}$ onto $\mathrm{Ta}_{3} \mathrm{~N}_{5}$ nanoparticles followed by heat treatment significantly improves the OER performance $\left(44 \mu \mathrm{mol} \mathrm{h}^{-1}\right)$. Modification of the $\mathrm{CoO}_{\mathrm{x}} / \mathrm{Ta}_{3} \mathrm{~N}_{5}$ photocatalyst with trace amounts of both Rh (see also Figure S5) and Ru (0.05 wt\%) further improves the performance by a factor of $\sim 3$, reaching a maximum rate of $133 \mu \mathrm{mol} \mathrm{h}{ }^{-1}$. The photocatalytic OER measured on samples not containing the $\mathrm{CoO}_{\mathrm{x}}$ phase $\left(\mathrm{RhO}_{\mathrm{x}} / \mathrm{Ta}_{3} \mathrm{~N}_{5}\right)$ showed no improvement in photocatalytic activity compared with bare $\mathrm{Ta}_{3} \mathrm{~N}_{5}$, as shown in Figure 1A, demonstrating that the improvement in OER efficiency is linked to synergistic effects between $\mathrm{CoO}_{\mathrm{x}}$ and noble metals ( $\mathrm{Ru}$ or Rh). Furthermore, the photocatalytic OER activity of $\mathrm{Rh}-\mathrm{CoO}_{\mathrm{x}} / \mathrm{Ta}_{3} \mathrm{~N}_{5}$ before and after heating under $\mathrm{H}_{2}$ did not show any significant difference, as shown in Figure S6. This result certifies that the oxidation state of active $\mathrm{Rh}$ and $\mathrm{Ru}$ species is in its oxidized form. The variation of $M$ actually shows a very sensitive trend: a loading of $0.05 \mathrm{wt} \%$ shows the maximized OER efficiency, whereas further loading decreased the OER efficiency, as shown in Figure S5. At $\mathrm{pH}$
10.5 (Figure 1A), the photocatalysts deactivated with time. During OER, the $\mathrm{pH}$ continuously decreased as the reaction consumed $\mathrm{OH}^{-}$(or produced $\mathrm{H}^{+}$), which would in turn affect the photocatalytic activity. Indeed, the $\mathrm{pH}$ value of 10.5 after several hours of reaction drastically decreased to an acidic $\mathrm{pH}(\sim 4-$ $5)$, where $\mathrm{CoO}_{\mathrm{x}}$ was no longer stable. To verify the impact of $\mathrm{pH}$, photocatalytic OER on $\mathrm{Rh} / \mathrm{CoO}_{\mathrm{x}} / \mathrm{Ta}_{3} \mathrm{~N}_{5}$ was also tested at pH 12 and 14, and the results are shown in Figure S7. As expected, oxygen was monotonically generated for a long period of time because of large concentration of $\mathrm{OH}^{-}$. Accordingly, $\mathrm{pH}$ after the reaction remained almost unchanged $(\mathrm{pH} \sim 11-13.5)$.

(A)
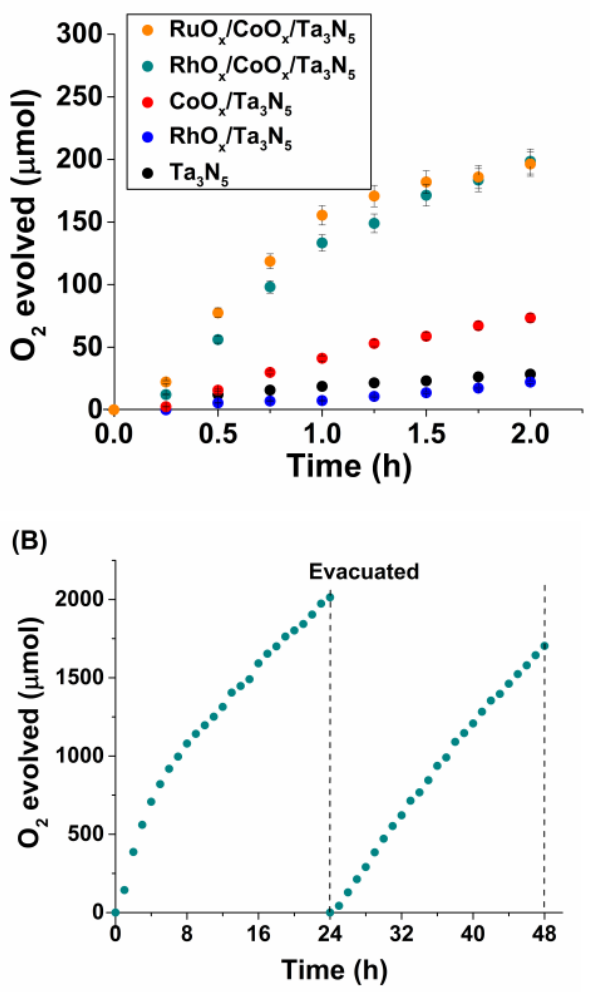

Figure 1. (A) Time courses of photocatalytic OER showing the effect of $\mathrm{RhO}_{\mathrm{x}} / \mathrm{CoO}_{\mathrm{x}} / \mathrm{Ta}_{3} \mathrm{~N}_{5}$ and $\mathrm{RuO}_{\mathrm{x}} / \mathrm{CoO}_{\mathrm{x}} / \mathrm{Ta}_{3} \mathrm{~N}_{5}(50 \mathrm{mg}, 0.1 \mathrm{M}$ $\mathrm{Na}_{2} \mathrm{~S}_{2} \mathrm{O}_{8}, \mathrm{pH} 10.5$ adjusted by $\left.\mathrm{NaOH}\right)$ under visible light irradiation $(420<\lambda<800 \mathrm{~nm})$ ); (B) photocatalytic reaction stability test using $\mathrm{RhO}_{x} / \mathrm{CoO}_{x} / \mathrm{Ta}_{3} \mathrm{~N}_{5}\left(50 \mathrm{mg}, 0.1 \mathrm{M} \mathrm{Na}_{2} \mathrm{~S}_{2} \mathrm{O}_{8}, \mathrm{pH} 14\right.$ adjusted by $\mathrm{NaOH}, 100 \mathrm{~mL}$, under visible light irradiation $(420<\lambda<800$ $\mathrm{nm})$ ).

To investigate the stability of the $\mathrm{RhO}_{\mathrm{x}} / \mathrm{CoO}_{\mathrm{x}}$ cocatalyst, the photocatalytic OER was conducted for up to 2-days at $\mathrm{pH} 14$; the result is depicted in Figure 1B. The OER rate was initially slightly higher and then reached a steady-state rate after $\sim 6 \mathrm{~h}$, evolving a total of $2 \mathrm{mmol}$ oxygen. The photocatalytic OER remained unchanged for the next $48 \mathrm{~h}$ after evacuation, indicating the excellent stability of $\mathrm{Ta}_{3} \mathrm{~N}_{5}$ and $\mathrm{RhO}_{\mathrm{x}} / \mathrm{CoO}_{\mathrm{x}}$ as the photocatalyst and OER cocatalyst, respectively. After this long-term test, the action spectra were taken to calculate the QE; the results are shown in Figure 2 (and summarized in Table S1). The QE estimated between 400 and $680 \mathrm{~nm}$ correlates well with the estimated absorbance of the $\mathrm{Ta}_{3} \mathrm{~N}_{5}$ samples (which agrees with previous reports (Figure S1)), ${ }^{7-18}$ which is consistent with the bandgap excitation of $\mathrm{Ta}_{3} \mathrm{~N}_{5}$. The QE was observed $>10 \%$ for wavelengths ranging between 440 and $520 \mathrm{~nm}$, with a maximum value of $30 \%$ at $480 \mathrm{~nm}$. The QE value at $500 \mathrm{~nm}(28 \%)$ 
is much higher than the highest $\mathrm{QE}$ value ever reported for $\mathrm{CoO}_{\mathrm{x}}$-loaded $\mathrm{Na}_{2} \mathrm{CO}_{3} / \mathrm{Ta}_{3} \mathrm{~N}_{5}$ and modified $\mathrm{MgO}-\mathrm{CoO}_{\mathrm{x}} / \mathrm{Ta}_{3} \mathrm{~N}_{5}$ for 500-600 nm wavelengths. ${ }^{19,22}$ In addition, a comparable QE value for $\mathrm{CoO}_{\mathrm{x}}$-loaded $\mathrm{LaTiO}_{2} \mathrm{~N}$ has been reported only at lower wavelengths $(27 \%$ at $440 \mathrm{~nm}) .{ }^{25}$ Nevertheless, the choice of $\mathrm{Na}_{2} \mathrm{~S}_{2} \mathrm{O}_{8}$ as a strong sacrificial reagent may give rise to undesired reaction pathways (leading, e.g. to sulfate radicals), and the $\mathrm{QE}$ values may not reflect the true photonic efficiency, as quoted in the literature. ${ }^{53}$ The choice of the reagent was, however, carefully conducted to be able to carry out the reactions under alkaline conditions ( $\mathrm{pH}$ 12-14) and an internal comparison of QE should be still valid. Separate experiments confirmed that no $\mathrm{O}_{2}$ was evolved under dark in the presence of photocatalyst or under illumination in the absence of photocatalyst. In our previous work, ${ }^{23}$ we compared the photocatalytic OER using different electron acceptors for $\mathrm{CoO}_{\mathrm{x}} / \mathrm{Ta}_{3} \mathrm{~N}_{5}$ samples. Figure $\mathrm{S} 8$ shows the comparison of photocatalytic OER on $\mathrm{CoO}_{x} / \mathrm{Ta}_{3} \mathrm{~N}_{5}$ in $\mathrm{AgNO}_{3}\left(\mathrm{pH}\right.$ 8.5, $\mathrm{La}_{2} \mathrm{O}_{3}$ buffer) and $\mathrm{Na}_{2} \mathrm{~S}_{2} \mathrm{O}_{8}(\mathrm{pH} 14, \mathrm{NaOH}$ adjusted). The OER rate in $\mathrm{AgNO}_{3}$ was higher than in $\mathrm{Na}_{2} \mathrm{~S}_{2} \mathrm{O}_{8}$, likely owing to the rapid kinetics of single electron transfer for $\mathrm{Ag}^{+}$ion reduction (thus expecting an even higher $\mathrm{QE}$ ), compared to sluggish multiple electron transfer for $\mathrm{S}_{2} \mathrm{O}_{8}{ }^{2-}$ ion reduction. However, $\mathrm{Ag}^{+}$reduction leads to deposition of metallic Ag particles on $\mathrm{Ta}_{3} \mathrm{~N}_{5}$ surface, and thus, strictly speaking, the process is not catalytic. More importantly, Ag cannot be used in strong alkaline solution as deposition of silver oxide occurs. For further characterization of the photocatalyst materials after the reaction, we selected $\mathrm{Na}_{2} \mathrm{~S}_{2} \mathrm{O}_{8}$ as an electron acceptor yielding a catalytic process which can be used in alkaline solution.

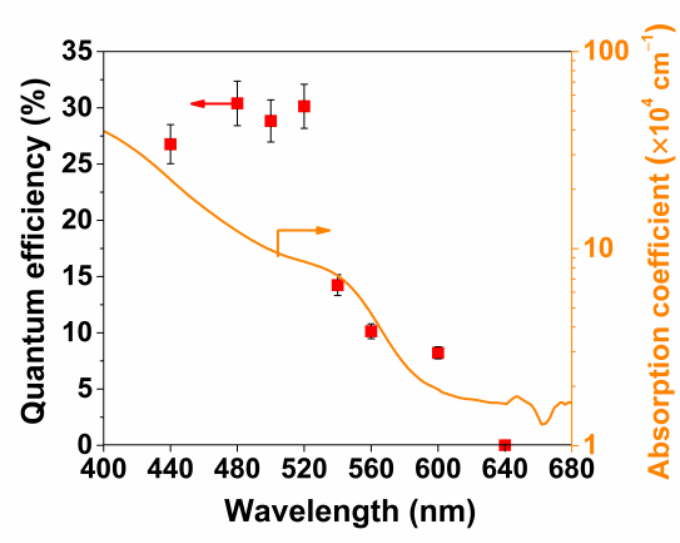

Figure 2. Quantum efficiency of $\mathrm{RhO}_{x} / \mathrm{CoO}_{x} / \mathrm{Ta}_{3} \mathrm{~N}_{5}$ and absorption coefficient of $\mathrm{Ta}_{3} \mathrm{~N}_{5}{ }^{21}$ (50 mg, $0.1 \mathrm{M} \mathrm{Na}_{2} \mathrm{~S}_{2} \mathrm{O}_{8}, \mathrm{pH} 14$ adjusted by $\mathrm{NaOH}, 100 \mathrm{~mL}, 300 \mathrm{~W}$ Xe lamp; the photon numbers are shown in Table S1).

To address the improvement of the OER performance occurring over the $M-\mathrm{CoO}_{x} / \mathrm{Ta}_{3} \mathrm{~N}_{5}$, separate electrochemical measurements of the active catalyst component isolated from the semiconductor led to a quantitative understanding of their electrocatalytic OER activity. Electrodes mimicking the $\mathrm{CoO}_{\mathrm{x}}$ and $M$-doped $\mathrm{CoO}_{x}$ on $\mathrm{Ta}_{3} \mathrm{~N}_{5}$ were prepared on various substrates of Co plate and Ni foam (NF). As a reference, a Ni plate was also used to evaluate the noble metal addition. Figure 3 shows the $i R$ corrected potential-current diagram and Tafel plots for $\mathrm{CoO}_{\mathrm{x}}$ and $M / \mathrm{CoO}_{\mathrm{x}}$. The addition of $M(\mathrm{Rh}$ and $\mathrm{Ru})$ drastically lowered the OER onset potential, consistent with the claims in the literature for other noble metals (Au, Ir, etc.). ${ }^{30-33}$ As a control experiment, the electrode with $M$ supported on an NF or Ni plate gave lower performance, exhibiting poorer OER activities of $M$ itself and/or little synergetic effects (Figure S9 and S10). The double layer capacitance $\left(C_{d l}\right)$, which is known to reflect an electrochemical active surface area, was also evaluated using impedance spectroscopy (Figure S11) and cyclic voltammograms (Figure S12). Figures S13 summarizes the obtained $C_{d l}$ of the electrodes. The $C_{d l}$ of $M / \mathrm{CoO}_{\mathrm{x}}$ and $M / \mathrm{NiO}_{\mathrm{x}}$ were found to be slightly greater than those of bare $\mathrm{CoO}_{\mathrm{x}}$ and $\mathrm{NiO}_{\mathrm{x}}(1-2$ times for the cobalt substrate at $1.5-1.6 \mathrm{~V}$ vs. RHE). The observed difference in $C_{d l}$, i.e., electrochemical active surface area, with/without noble metal addition was, however, much smaller than the difference in the OER activity. This observation clearly excludes the possibility that the enhanced OER performance simply originates from the increase in the surface area. Figure S14 provides measured charge transfer resistances of the electrodes by impedance data fitting. Noble metal addition to $\mathrm{CoO}_{\mathrm{x}}$, particularly $\mathrm{RhO}_{\mathrm{x}} / \mathrm{CoO}_{\mathrm{x}}$, significantly lowered the charge transfer resistance, which is consistent with the improved OER activity. These results confirm that the electrocatalytic OER was improved by the metal doping and that synergistic effects between Co and $M$ were present. Although the noble metal addition resulted in an improved OER performance, it did not significantly alter the Tafel slope $\left(\sim 40 \mathrm{mV} \mathrm{dec}{ }^{-1}\right)$. These observations suggest that a similar reaction mechanism is prevalent, but that the intrinsic catalytic activity should be improved by $\mathrm{Rh}$ or $\mathrm{Ru}$ addition (i.e., enlargement in exchange current). The potential of the cocatalyst during the photocatalysis is shifted as a consequence of hole transfer, and even if the extent of the shift is identical between $\mathrm{CoO}_{\mathrm{x}}$ and $M / \mathrm{CoO}_{\mathrm{x}}$, the doped one will benefit from photocatalytic OER kinetics.

The mechanistic insight during electrocatalytic OER was further investigated by DFT calculations. The evaluation of the thermodynamic overpotential was performed using the protocol proposed by Bajdich et al. ${ }^{42}$ This protocol is presented briefly in the experimental section and more precisely in Supporting Information (section S4.1). In brief, the overpotential is imposed by the larger free energy (equations (6)-(9)) of the four steps of the catalytic cycle (equations (2)-(5)). The computed geometries for each of the four steps are presented in Figure 4 for the non-doped situation.

The overpotential was computed for the following scenario:

(i) The reaction happens on a Co atom on the nondoped surface.

(ii) The reaction happens on a Co atom with one dopant substituting the first neighbor Co.

(iii) The reaction happens on the dopant that substitutes one Co atom.

The computed thermodynamic overpotentials are presented in Table 1. It is clearly shown that Ru(IV) and $\mathrm{Rh}(\mathrm{IV})$ dopants make reaction energies more similar for the four steps, therefore enhancing the catalytic activity of surface Co atoms (see Figures S15-S17 for all the intermediate structures for the reaction, which happen in the presence of Ru(IV) and Rh(IV), all computed $\Delta G_{\mathrm{i}}$, and bond length and charges). The rate enhancement induced by $\mathrm{Rh}(\mathrm{IV})$ and $\mathrm{Ru}(\mathrm{IV})$ is the consequence of a decrease of the reaction energy $\Delta G_{3}$ (corresponding to the $* \mathrm{O} \rightarrow * \mathrm{OOH}$ step). The cause of this energy decrease is different for Rh(IV) and $\mathrm{Ru}(\mathrm{IV})$ dopings. For the $\mathrm{Rh}(\mathrm{IV})$, it is caused by a stabilization of the ${ }^{*} \mathrm{OOH}$ state, and for the $\mathrm{Ru}(\mathrm{IV})$, it is due to a destabilization of the $* \mathrm{O}$ state (see supporting information for more 
discussion). Interestingly, for $\mathrm{Rh}(\mathrm{III})$ and large decrease (resp. increase) of $\Delta G_{1}$ (resp. $\Delta G_{4}$ ) is computed. This is ascribed to a large destabilization of the surface vacancy state $*$ itself as a consequence of the low spin state of $\mathrm{Co}(\mathrm{II})$ induced by $\mathrm{Rh}(\mathrm{III})$.

(A)

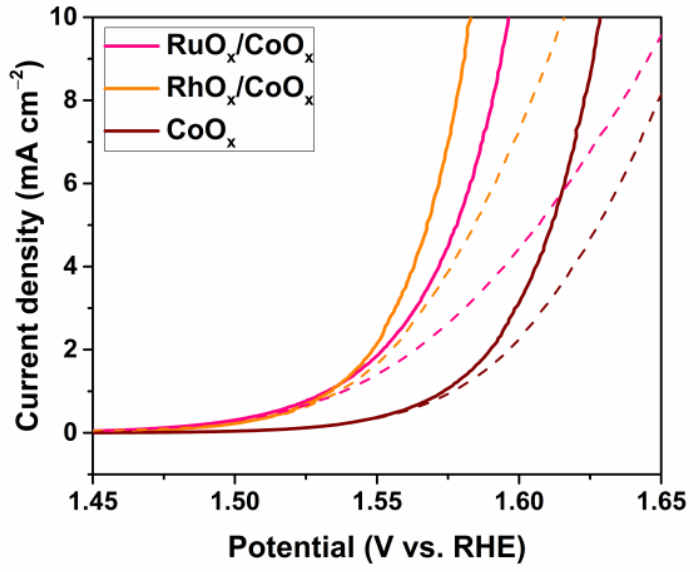

(B)

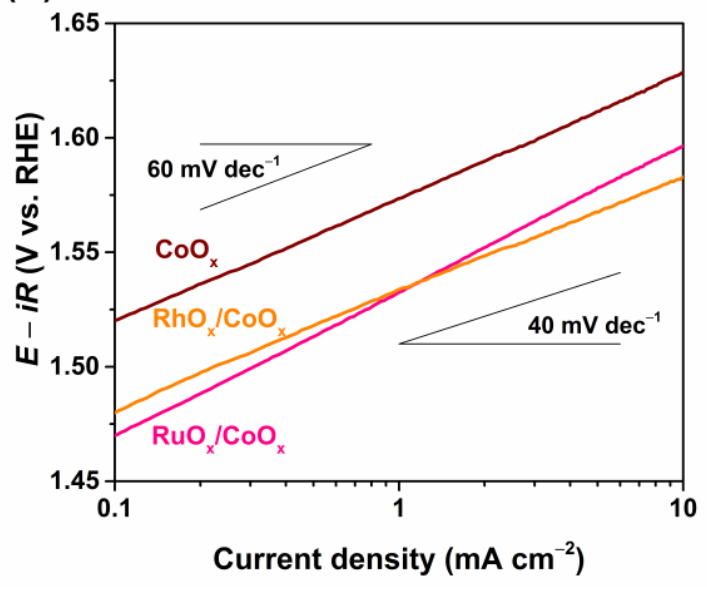

Figure 3. (A) Linear-sweep voltammograms (LSVs) and (B) Tafel plots over various electrodes: $\mathrm{RhO}_{\mathrm{x}} / \mathrm{CoO}_{\mathrm{x}}, \mathrm{RuO}_{\mathrm{x}} / \mathrm{CoO}_{\mathrm{x}}$, $\mathrm{CoO}_{\mathrm{x}}$. Measurements were carried out in $1.0 \mathrm{M} \mathrm{NaOH}$ electrolyte solution with $\mathrm{O}_{2}$ bubbling at a $-1 \mathrm{mV} \mathrm{s}^{-1}$ scan rate and at $298 \mathrm{~K}$. Solid line: with $i R$ correction. Dotted line: without $i R$ correction.

The dopants are not themselves good catalysts for the OER, as highlighted by the higher overpotential computed for these reaction paths compared with reactions performed on the Co atom. A large amount of dopants will inhibit the catalytic activity of the system because the concentration of Co on the surface will reduce and the dopants are not efficient for catalysis. This explains the experimental result, that is, a reduction of the catalytic activity for a large amount of dopant (Figure S5).

Table 1. Computed overpotential (in V) for reaction occurring on Co atom ("On Co" line) or on the dopant ("On dopant" line).

\begin{tabular}{lllll}
\hline & Non-doped & $\mathrm{Rh}(\mathrm{III})$ & $\mathrm{Rh}(\mathrm{IV})$ & $\mathrm{Ru}(\mathrm{IV})$ \\
\hline On Co & 0.61 & 0.64 & 0.40 & 0.42 \\
On dopant & -- & 0.95 & 0.67 & 1.16 \\
\hline
\end{tabular}

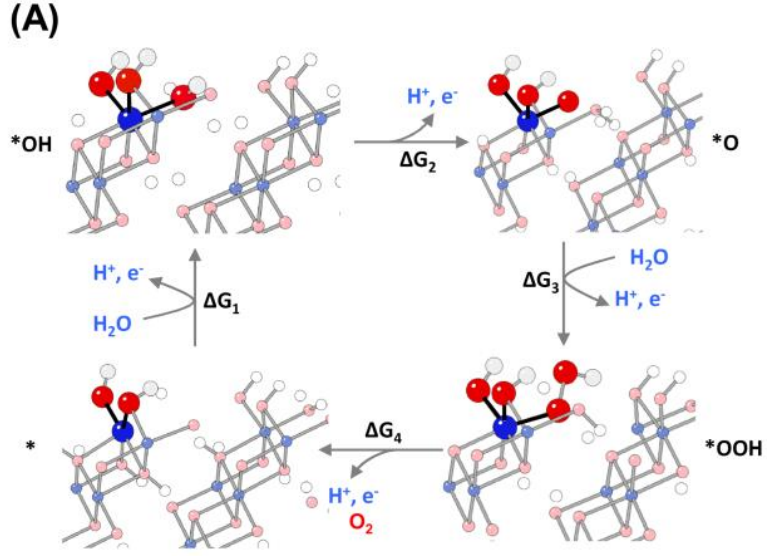

(B)

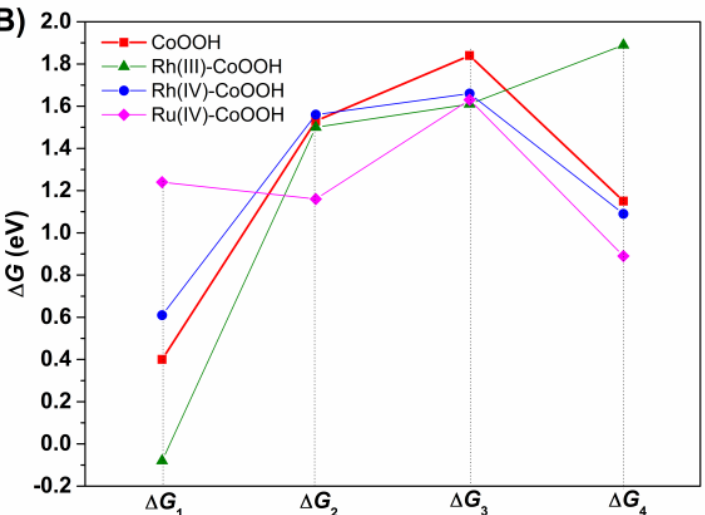

Figure 4. (A) Scheme of surface intermediates along the four elementary steps for oxygen evolution reaction; (B) Gibbs free energy for the four steps described in (A) for reaction happening on a Co atom using non-doped and $M-\mathrm{CoOOH}$.

To gain further insight into the improved OER performance of the nanocomposites after noble metal addition, we characterized carrier dynamics for the samples by using TRTS. ${ }^{38}$ The photoconductivity dynamics were found to be linear, with the pump fluence up to $200 \mu \mathrm{J} \mathrm{cm}$ and a $400 \mathrm{~nm}$ excitation. In Figure 5, we compare carrier dynamics inferred by TRTS for bare $\quad \mathrm{Ta}_{3} \mathrm{~N}_{5}, \quad \mathrm{CoO}_{\mathrm{x}} / \mathrm{Ta}_{3} \mathrm{~N}_{5}, \quad \mathrm{RhO}_{\mathrm{x}} / \mathrm{CoO}_{\mathrm{x}} / \mathrm{Ta}_{3} \mathrm{~N}_{5}$ and $\mathrm{RuO}_{\mathrm{x}} / \mathrm{CoO}_{\mathrm{x}} / \mathrm{Ta}_{3} \mathrm{~N}_{5}$ at $400 \mathrm{~nm}$ excitation (greater than the $\mathrm{Ta}_{3} \mathrm{~N}_{5}$ bandgap). We find that, while the long-lived ns dynamics overlap for all sample recipes (see Figure 5A), the ultrafast real photoconductivity for short pump-probe delays becomes negative upon decoration of $\mathrm{Ta}_{3} \mathrm{~N}_{5}$ with $\mathrm{CoO}_{\mathrm{x}}$ and $M-\mathrm{CoO}_{\mathrm{x}}$ phases (see Figure 5B). Provided that the overall TRTS response reflects a combination of electron $(e)$ and hole $(h)$ dynamics in the samples $\left(\operatorname{Re}(\sigma)=N_{e} \times \mu_{e}+N_{h} \times \mu_{h}\right.$; where $N$ and $\sigma$ represent number of carriers and mobility), and that the $\mathrm{CoO}_{\mathrm{x}}$ and $M / \mathrm{CoO}_{\mathrm{x}}$ decoration is expected to affect primarily hole dynamics, we can tentatively assign the identical long-lived components to electrons populating the $\mathrm{Ta}_{3} \mathrm{~N}_{5}$ conduction band. On the other hand, regarding the short-lived dynamics, as $\mathrm{THz}$ stimulated emission was ruled out experimentally, the observation of a pump-induced negative conductivity must be linked with carrier heating in the metallic phases of the samples. ${ }^{54-56}$ Unfortunately, this inhibits the unambiguous quantification of hole transfer processes from $\mathrm{Ta}_{3} \mathrm{~N}_{5}$ to the $\mathrm{CoO}_{x}$ phases. In any case, as evident from Figure 5B (see also Figure S18), the strength of the pump induced negative real conductivity associated with the $\mathrm{CoO}_{\mathrm{x}}$ phase is clearly enhanced after $M$ decoration. This demonstrates 
that metal addition on $\mathrm{CoO}_{\mathrm{x}}$ have an impact in the short-lived sample's pump induced charge dynamics, the time window of which is characteristic for the hole dynamics in bare $\mathrm{Ta}_{3} \mathrm{~N}_{5}$ samples as discussed below.
(A)

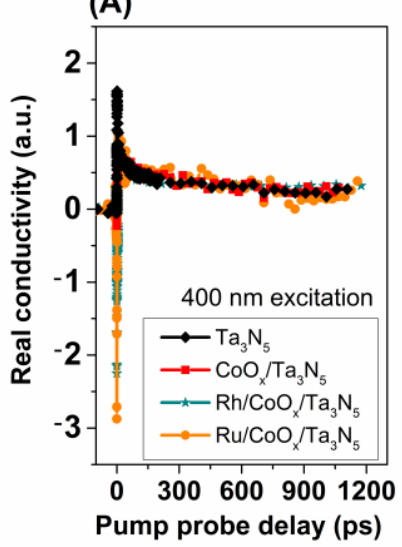

(B)

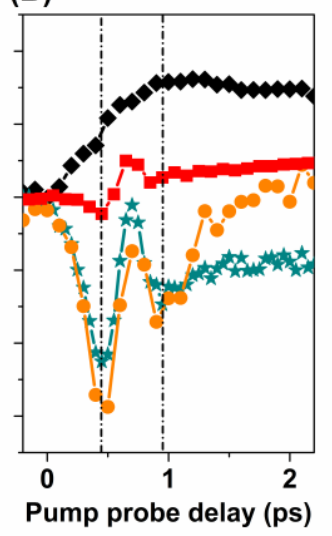

Figure 5. OPTP dynamics, normalized to the long-lived plateau at $1200 \mathrm{ps}$, under $400 \mathrm{~nm}$ excitation for $\mathrm{Ta}_{3} \mathrm{~N}_{5}$ (black diamonds), $\mathrm{CoO}_{\mathrm{x}} / \mathrm{Ta}_{3} \mathrm{~N}_{5}$ (red squares), $\mathrm{RuO}_{\mathrm{x}} / \mathrm{CoO}_{\mathrm{x}} / \mathrm{Ta}_{3} \mathrm{~N}_{5}$ (orange circles) and $\mathrm{RhO}_{\mathrm{x}} / \mathrm{CoO}_{\mathrm{x}} / \mathrm{Ta}_{3} \mathrm{~N}_{5}$ (cyan stars) samples under an $\mathrm{N}_{2}$ atmosphere. (A) and (B) indicate the same data but different time scale.
(A)

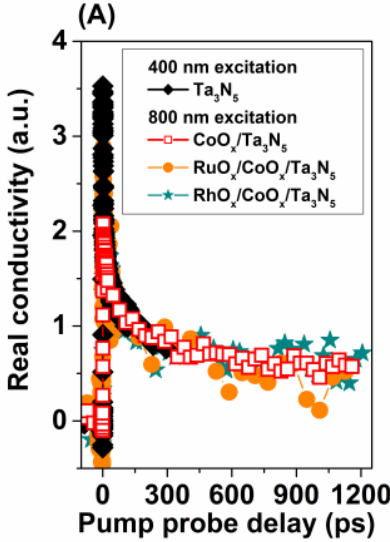

(B)

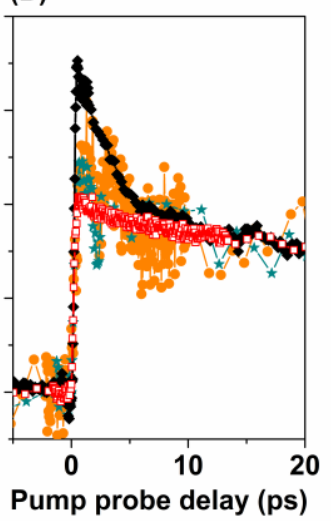

Figure 6. OPTP dynamics, normalized to the long-lived plateau at $1200 \mathrm{ps}$, under $400 \mathrm{~nm}$ excitation for $\mathrm{Ta}_{3} \mathrm{~N}_{5}$ (black diamonds) and under $800 \mathrm{~nm}$ excitation for $\mathrm{CoO}_{\mathrm{x}} / \mathrm{Ta}_{3} \mathrm{~N}_{5}$ (red squares), $\mathrm{RuO}_{\mathrm{x}} / \mathrm{CoO}_{\mathrm{x}} / \mathrm{Ta}_{3} \mathrm{~N}_{5}$ (orange circles) and $\mathrm{RhO}_{\mathrm{x}} / \mathrm{CoO}_{\mathrm{x}} / \mathrm{Ta}_{3} \mathrm{~N}_{5}$ (cyan stars) samples under an $\mathrm{N}_{2}$ atmosphere. (A) and (B) indicate the same data but different time scale.

In Figure 6, we compare carrier dynamics inferred by TRTS for bare $\mathrm{Ta}_{3} \mathrm{~N}_{5}$ at $400 \mathrm{~nm}$ excitation and $\mathrm{CoO}_{\mathrm{x}} / \mathrm{Ta}_{3} \mathrm{~N}_{5}$, $\mathrm{RhO}_{\mathrm{x}} / \mathrm{CoO}_{\mathrm{x}} / \mathrm{Ta}_{3} \mathrm{~N}_{5}$ and $\mathrm{RuO}_{\mathrm{x}} / \mathrm{CoO}_{\mathrm{x}} / \mathrm{Ta}_{3} \mathrm{~N}_{5}$ at $800 \mathrm{~nm}$ excitation. The data are also normalized at 1200 ps. In contrast to the 400 $\mathrm{nm}$ excitation beyond $\mathrm{Ta}_{3} \mathrm{~N}_{5}$ bandgap, a $800 \mathrm{~nm}$ excitation is able to photoexcite only the $\mathrm{CoO}_{x}$ phases. As expected, no response was observed at $800 \mathrm{~nm}$ for the bare $\mathrm{Ta}_{3} \mathrm{~N}_{5}$ sample. Consequently, the fact that the long-lived (ns timescale) photoconductivity dynamics are identical in all of the systems (Figure 6A) demonstrates that electron transfer from the nano-scaled $\mathrm{CoO}_{\mathrm{x}}$ phase to the bulk-like $\mathrm{Ta}_{3} \mathrm{~N}_{5}$ phase is efficient in the $(M) / \mathrm{CoO}_{\mathrm{x}} / \mathrm{Ta}_{3} \mathrm{~N}_{5}$ samples. This electron transfer also suggests that the presence of a type II-like band alignment between $\mathrm{CoO}_{x}$ and $\mathrm{Ta}_{3} \mathrm{~N}_{5}$ phases. To further support this scenario, TRTS measurements were conducted on the samples consisting on $\mathrm{CoO}_{\mathrm{x}}$ and $M / \mathrm{CoO}_{\mathrm{x}}$ supported on $\mathrm{SiO}_{2}$, which were prepared with exactly the same treatment as $\mathrm{Ta}_{3} \mathrm{~N}_{5}$ samples. No TRTS real conductivity signal was resolved for all the $\mathrm{SiO}_{2}$ supported samples, consistent with lack of electron transfer on the type I-like band alignment between $\mathrm{CoO}_{\mathrm{x}}$ and $\mathrm{SiO}_{2}$. Furthermore, the identical long-lived components present for all samples, including bare $\mathrm{Ta}_{3} \mathrm{~N}_{5}$, can be unambiguously assigned to electrons populating the $\mathrm{Ta}_{3} \mathrm{~N}_{5}$ conduction band. These electrons do not experience enhanced recombination after the addition of $\mathrm{CoO}_{x}$-related phases, e.g., $\mathrm{CoO}_{\mathrm{x}}$ or $M / \mathrm{CoO}_{\mathrm{x}}$ addition to $\mathrm{Ta}_{3} \mathrm{~N}_{5}$ does not promote surface acceptors in the latter (at least to the extent that can affect carrier dynamics within the $\sim 1$ ns time window). As evident from Figure $6 \mathrm{~B}$, the dynamics within the first $10 \mathrm{ps}$ are different between the two excitation cases; this strongly suggests that the short-lived component resolved in pure $\mathrm{Ta}_{3} \mathrm{~N}_{5}$ samples under $400 \mathrm{~nm}$ excitation is a signature of ultrafast trapping of the holes in defects of the $\mathrm{Ta}_{3} \mathrm{~N}_{5}$ phase. Such short carrier lifetime was reported at $8 \mathrm{ps}$ for $\mathrm{Ta}_{3} \mathrm{~N}_{5}$ by the time resolved spectroscopies. ${ }^{18}$ In addition, the dynamics of $\mathrm{Ta}_{3} \mathrm{~N}_{5}$ in Figure 6 reveal that the weights of the long-lived electrons and the short-lived holes are roughly equal, indicating that electron and hole mobilities in the $\mathrm{Ta}_{3} \mathrm{~N}_{5}$ phase are rather similar. This observation agrees well with similar effective masses for electrons and holes theoretically estimated for $\mathrm{Ta}_{3} \mathrm{~N}_{5} .{ }^{57,58}$ The ultrafast quenching of holes at the $\mathrm{Ta}_{3} \mathrm{~N}_{5}$ phase is consistent with its poor OER performance (provided that trapped holes are not energetically suitable to promote OER after trapping). From $\mathrm{THz}$ characterization, we cannot conclude whether the hole traps are present in the surface or in the bulk phase. The improvement of OER performance for the $\mathrm{CoO}_{\mathrm{x}} / \mathrm{Ta}_{3} \mathrm{~N}_{5}$ sample compared with the bare $\mathrm{Ta}_{3} \mathrm{~N}_{5}$ sample, although not directly revealed by the TRTS measurements, could correlate with a kinetic competition between hole trapping at the $\mathrm{Ta}_{3} \mathrm{~N}_{5}$ and $\mathrm{CoO}_{x}$ phases; the scavenging of holes toward the $\mathrm{CoO}_{\mathrm{x}}$ phases will be favored for samples containing noble metals if the relative band offset between $\mathrm{Ta}_{3} \mathrm{~N}_{5}$ and $\mathrm{CoO}_{x}$ is appropriately shifted after metal addition (a consequence of enhanced donor-acceptor free Gibbs energy gap; in good agreement with the following DFT results).

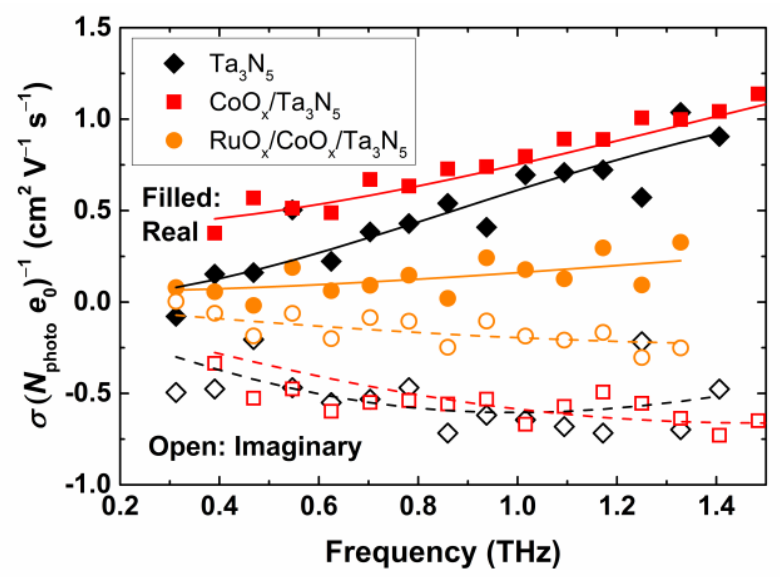

Figure 7. THz photoconductivity measured at the photoexcitation wavelength of $400 \mathrm{~nm}$ (photoexcitation fluence $100 \mu \mathrm{J} \mathrm{cm}^{-2}$ ) for a pump-probe delay time of $200 \mathrm{ps}$. The closed symbols represent the real part and the open symbols show the imaginary part of the photoconductivity. The lines represent the fit of the spectra using the Drude-Smith model. 


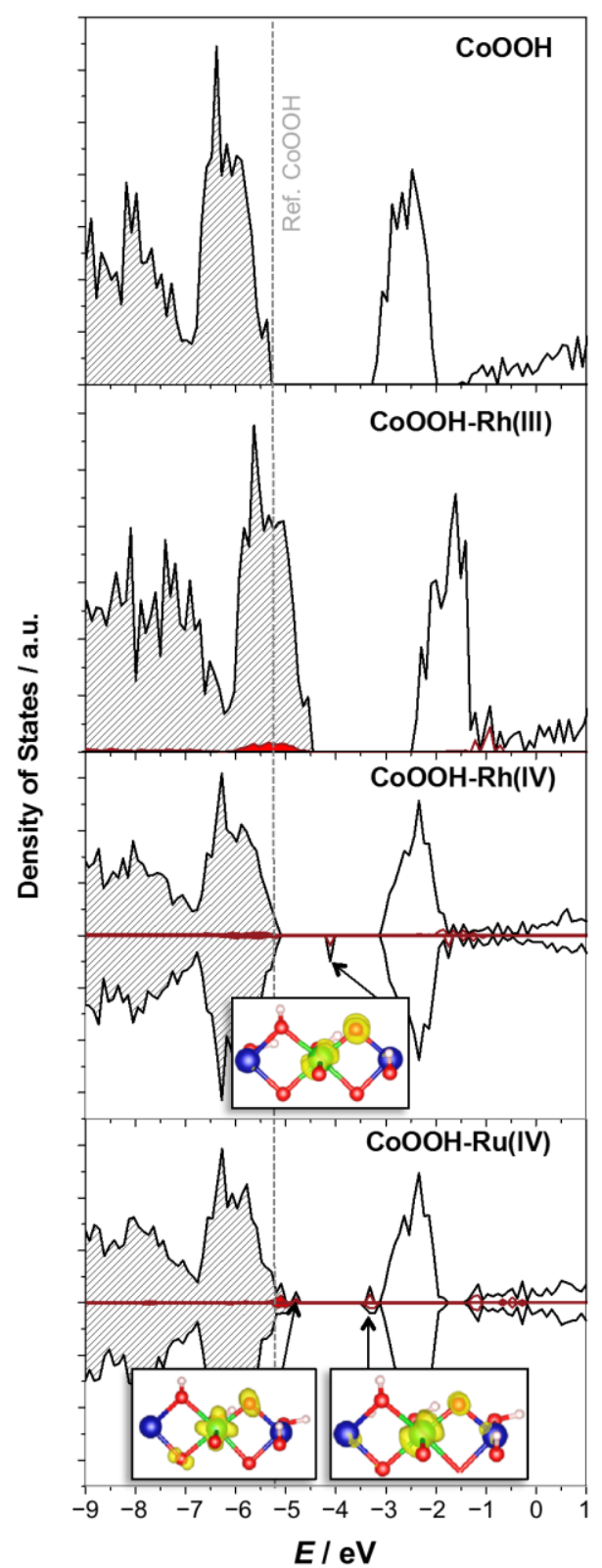

Figure 8. Calculated DOS of the computed of the pure $\mathrm{CoOOH}$ surface and the doped $\mathrm{CoOOH}$ surfaces. The energy reference is the vacuum level. Black curves are the total DOS and red curves are the projected DOS on the dopant. Filled and empty areas correspond to occupied and unoccupied states, respectively. Inset: Isosurface of the square of the moduli of selected states. Red, blue, white and green atoms are oxygen, cobalt, hydrogen and dopant, respectively.

To interrogate the nature of electron transport in bare and decorated $\mathrm{Ta}_{3} \mathrm{~N}_{5}$ phases, we measured the complex ac photoconductivity spectra of the samples in the $\mathrm{THz}$ frequency range. Figure 7 shows the obtained photoconductivity response (normalized by the photon density). In Figure 7, the real part of the photoconductivity increases with the frequency and the imaginary part of the conductivity is negative. This is the characteristic signature of the transport of localized carriers, which can be modeled by using the Drude-Smith model,

$$
\sigma(\omega)=\frac{\sigma_{\mathrm{DC}}}{1-i \omega \tau}\left(1+\frac{c}{1-i \omega \tau}\right) .
$$

This model is a phenomenological model commonly used for transport in disordered systems. ${ }^{38}$ Here, $\sigma_{\mathrm{DC}}$ is the extrapolated DC conductivity, $\tau$ is the scattering time and $c$ characterizes the measure of back-scattering of carriers in the sample. For all samples, we find $c$ parameters between -0.9 and -1 , which is indicative of electrons being confined at a length scale comparable to the size of a single $\mathrm{Ta}_{3} \mathrm{~N}_{5}$ nanocrystal. From the data in Figure 7, we infer mobilities of electrons in the $\mathrm{Ta}_{3} \mathrm{~N}_{5}$ phase of $\mu \sim 0.1-3 \mathrm{~cm}^{2} \mathrm{~V}^{-1} \mathrm{~s}^{-1}$.

If $\mathrm{Rh}$ or $\mathrm{Ru}$ is incorporated into the $\mathrm{CoO}_{\mathrm{x}}$ structure, there should be an influence on the electronic structure. Density of states (DOS) of these systems estimated by DFT calculation are shown in Figure 8, which analyzes the variations of electronic structures at band edges. It is shown that the valence band positions are positively shifted by doping. The top of the valence band has a contribution from the dopant but, in all cases, these states above the reference energy of $\mathrm{CoOOH}$ have a larger contribution from the bulk $\mathrm{CoOOH}$ material $(>95 \%)$ than the dopant $(<5 \%)$. These increases in the energy of the valence band edge upon doping improve the thermodynamic of the charge transfer and consequently its kinetics. Such small increase of valence band edge energy sufficiently accounts for an improvement of charge transfer efficiency. ${ }^{59-61}$ For the Rh(IV) and $\mathrm{Ru}(\mathrm{IV})$ doping, states localized on the dopant and oxygen atoms linked to the dopant clearly appear within the bandgap. These intermediate dopant states are responsible for the variation of the valence and conduction band edge energies. These results support the TRTS experiments, where a kinetic competition between hole transfer toward the $\mathrm{CoO}_{\mathrm{x}}$ phase and trapping at the $\mathrm{Ta}_{3} \mathrm{~N}_{5}$ phase is suggested.

\section{Conclusions}

We have shown a simple and effective method for improving the photocatalytic OER rate of $\mathrm{CoO}_{\mathrm{x}} / \mathrm{Ta}_{3} \mathrm{~N}_{5}$ by adding a trace amount of Ru or Rh. By using electrochemistry and TRTS, we have provided experimental evidence where the possible causes of enhanced photocatalytic OER are two-fold: improved electrocatalysis and charge transfer. TRTS measurements demonstrate that $\mathrm{Ta}_{3} \mathrm{~N}_{5}$ phases alone suffer ultrafast hole trapping; the $\mathrm{CoO}_{\mathrm{x}}$ decoration must induce a kinetic competition between hole transfer toward the $\mathrm{CoO}_{\mathrm{x}}$ phase and trapping at the $\mathrm{Ta}_{3} \mathrm{~N}_{5}$ phase (which could be linked with OER improvement); reducing the work functions of $\mathrm{CoO}_{x}$ phases after noble metal addition (as revealed by DFT) will necessarily increase the free Gibbs energy for hole transfer toward the $\mathrm{CoO}_{x}$ phases, and then the kinetic competition between hole trapping at $\mathrm{Ta}_{3} \mathrm{~N}_{5}$ and transfer from the $\mathrm{Ta}_{3} \mathrm{~N}_{5}$ phase toward $M-\mathrm{CoO}_{\mathrm{x}}$ should be favored for the latter (and, accordingly, the OER efficiency). In addition, Co sites neighboring dopant ions present a lower overpotential and therefore are more active for electrocatalytic OER, evident by electrochemical measurements and DFT. This study demonstrates the clear advancement of powder-photocatalyst characterization in combination with first-principle modeling for designing highly efficient solar energy conversion devices.

\section{ASSOCIATED CONTENT}

Supporting Information. Detailed experimental, physical and chemical characterizations are presented in Supporting Information. This material is available free of charge via the Internet at http://pubs.acs.org. 


\section{AUTHOR INFORMATION}

\author{
Corresponding Author \\ * Kazuhiro Takanabe, \\ E-mail: kazuhiro.takanabe@kaust.edu.sa
}

\section{ACKNOWLEDGMENT}

The research reported in this work was supported by the King Abdullah University of Science and Technology. The authors also acknowledge the PSN and IDRIS computation centers for providing calculation resources.

\section{REFERENCES}

1. Takanabe, K.; Domen, K. Green 2011, 1, 313-322.

2. Tong, H.; Ouyang, S.; Bi, Y.; Umezawa, N.; Oshikiri, M.; Ye, J. J. Adv. Mater. 2012, 24, 229-25.

3. Maeda, K.; Domen, K. J. Phys. Chem. Lett. 2010, 1, 26552661.

4. Kudo, A.; Miseki, Y.; Chem. Soc. Rev. 2009, 38, 253-278.

5. Maeda, K.; Domen, K. J. Phys. Chem. C 2007, 111, 78517861.

6. Abe, R. J. Photochem. Photobiol. C 2010, 11, 179-209.

7. Chen, W.; Ishikawa, A.; Fujisawa, H.; Takata, T.; Kondo, J. N.; Hara, M.; Kawai, M.; Matsumoto, Y.; Domen, K. J. Phys. Chem. B 2003, 107, 1798-1803.

8. Hara, M.; Hitoki, G.; Takata, T.; Kondo, J. N.; Kobayashi, H.; Domen, K. Catal. Today 2003, 78, 555-560.

9. Hitoki, G.; Ishikawa, A.; Takata, T.; Kondo, J. N.; Hara, M.; Domen, K. Chem. Lett. 2002, 7, 736-737.

10. Li, M.; Luo, W.; Cao, D.; Zhao, X.; Li, Z.; Yu, T.; Zou, Z. Angew. Chem. Int. Ed., 2013, 52, 11016-11020.

11. Li, Y.; Takata, T.; Cha, D.; Takanabe, K.; Minegishi, T.; Kubota, J.; Domen, K. Adv. Mater. 2013, 25, 125-131.

12. Gao, R.; Hu, L.; Chen, M.; Wu, L. Small, 2014, 10, 15, 30383044

13. Liu, G.; Shi, J.; Zhang, F.; Chen, Z.; Han, J.; Ding, C.; Chen, S.; Wang, Z.; Han, H.; Li, C. Angew. Chem. Int. Ed. 2014, 53, 7295-7299.

14. Hara, M.; Chiba, E.; Ishikawa, A.; Takata, T.; Kondo, J. N.; Domen, K. J. Phys. Chem. B 2003, 107, 13441-13445.

15. Ishikawa, A.; Takata, T; Kondo, J. N.; Hara, M.; Domen, K. J. Phys. Chem. B 2004, 108, 11049-11053.

16. Nurlaela, E.; Ould-Chikh, S.; Harb, M.; del Gobbo, S.; Aouine, M.; Puzenat, E.; Sautet, P.; Domen, K.; Basset, J-M.; Takanabe, K. Chem. Mater. 2014, 26, 4812-4825.

17. Fukasawa, Y.; Takanabe, K.; Shimojima, A.; Antonietti, M.; Domen, K.; Okubo, T. Chem. Asian J. 2011, 6, 103-109.

18. Ziani, A.; Nurlaela, E.; Dhawale, D. S.; Silva, D. A.; Alarousu, E.; Mohammed, O. F.; Takanabe, K. Phys. Chem. Chem. Phys. 2015, 17, 2670-2677.

19. Chen, S.; Shen, S.; Liu, G.; Qi, Y.; Zhang, F.; Li, C. Angew. Chem. Int. Ed. 2015, 54, 3047 -3051.

20. Seo, J.; Takata, T.; Nakabayashi, M.; Hisatomi, T.; Shibata, N.; Minegishi, T.; Domen, K. J. Am. Chem. Soc. 2015, 137, 12780-12783.

21. Suzuki, S.; Wagata, H.; Komatsu, M.; Minegishi, T.; Domen, K.; Oishi, S.; Teshima, K. J. Mater. Chem. A 2015, 3, 1394613952.

22. Ma, S. S. K.; Hisatomi, T.; Maeda, K.; Moriya, Y.; Domen, K. J. Am. Chem. Soc. 2012, 134, 19993-19996.

23. Nurlaela, E.; Ould-Chikh, S.; Llorens , I.; Hazemann, J.-L.; Takanabe, K. Chem. Mater. 2015, 27, 5685-5694.

24. Nurlaela, E.; Shinagawa, T.; Qureshi, M.; Dhawale, D. S.; Takanabe, K. ACS Catal. 2016, 6, 1713-1722.

25. Zhang, J. F.; Yamakata, A.; Maeda, K.; Moriya, Y.; Takata, T.; Kubota, J.; Teshima, K.; Oishi, S.; Domen. K. J Am. Chem. Soc. 2012, 134, 8348-8351.
26. Ran, J.; Zhang, J.; Yu, J.; Jaroniec, M.; Qiao, S. Z. Chem. Soc. Rev. 2014, 43, 7787-7812.

27. Zhong, D. K.; Choi, S.; Gamelin, D. R. J. Am. Chem. Soc. 2011, 133, 18370-18377.

28. Seabold, J. A.; Choi, K.-S. Chem. Mater. 2011, 23, 1105-1112.

29. Lin, F.; Boettcher, S. W. Nat. Mater. 2014, 13, 81-86.

30. Yeo, B. S.; Bell, A. T. J. Am. Chem. Soc. 2011, 133, 55875593.

31. Zhang, M.; de Respinis, M.; Frei, H. Nat. Chem. 2014, 6, 362367.

32. Klingan, K.; Ringleb, F.; Zaharieva, I.; Heidkamp, J.; Chernev, P.; Gonzalez-Flores, D.; Risch, M.; Fischer, A.; Dau, H. ChemSusChem 2014, 7, 1301-1310.

33. Tae, E. L.; Song, J.; Lee, A. R.; Kim, C. H.; Yoon, S.; Hwang, I.C.; Kim, M. G.; Yoon, K. B. ACS Catal. 2015, 5, 5525-5529.

34. Higashi, M.; Domen, K.; Abe, R. J. Am. Chem. Soc. 2013, 135, 10238-10241.

35. Barroso, M.; Cowan, A. J.; Pendlebury, S. R.; Gratzel, M.; Klug, D. R.; Durrant, J. R.; J. Am. Chem. Soc. 2011, 133, 14868-14871.

36. Barroso, M.; Mesa, C.A.; Pendlebury, S.R.; Cowan, A. J.; Hisatomi, T.; Sivula, K.; Grätzel, M.; Klug, D. R.; Durrant, J. R. PNAS 2012, 109, 15640-15645.

37. Reynal, A.; Lakadamyali, F.; Gross, M. A.; Reisner, E.; Durrant, J. R. Energy Environ. Sci. 2013, 6, 3291-3300.

38. Ulbricht, R.; Hendry, E.; Shan, J.; Heinz, T. F.; Bonn, M. Rev Mod. Phys. 2011, 83, 543-586.

39. Kresse, G.; Joubert, D. Phys. Rev. B 1999, 59, 1758-1775.

40. Kresse, G.; Furthmüller, J. Phys. Rev. B 1996, 54, 1116911186.

41. Kresse, G.; Furthmüller, J. Comput. Mater. Sci. 1996, 6, 15-50.

42. Perdew, J. P.; Ernzerhof, M.; Burke, K. J. Chem. Phys. 1996, 105, 9982-9985

43. Chen, J.; Wu, X.; Selloni, A. Phys. Rev. B 2011, 83, 245204

44. Bajdich, M.; García-Mota, M.; Vojvodic, A.; Nørskov, J. K.; Bell, A. T. J. Am. Chem. Soc. 2013, 135, 13521-13530.

45. García-Mota, M.; Bajdich, M.; Viswanathan, V.; Vojvodic, A.; Bell, A. T.; Nørskov, J. K. J. Phys. Chem. C 2012, 116, 21077 21082.

46. Friebel, D.; Louie, M. W.; Bajdich, M.; Sanwald, K. E.; Cai, Y.; Wise, A. M.; Cheng, M.-J.; Sokaras, D.; Weng, T.-C.; Alonso-Mori, R.; Davis, R. C.; Bargar, J. R.; Nørskov, J. K.; Nilsson, A.; Bell, A. T., J. Am. Chem. Soc. 2015, 137, 13051313

47. Dudarev, S. L.; Savrasov, S. Y.; Humphreys, C. J.; Sutton, A. P. Phys. Rev. B 1998, 57, 1505-1509.

48. Liu, C.-J.; Sheu, C.-S.; Wu, T.-W.; Huang, L.-C.; Hsu, F. H.; Yang, H. D.; Williams, G. V. M.; Liu, C.-J. C. Phys. Rev.B 2005, 71, 014502 .

49. Paudel, T. R.; Lany, S.; D’Avezac, M.; Zunger, A.; Perry, N. H.; Nagaraja, A. R.; Mason, T. O.; Bettinger, J. S.; Shi, Y.; Toney, M. F. Phys. Rev. B 2011, 84, 064109.

50. Henkelman, G.; Arnaldsson, A.; Jónsson, H. Comput. Mater Sci. 2006, 36, 354-360.

51. Nørskov, J. K.; Rossmeisl, J.; Logadottir, A.; Lindqvist, L.; Kitchin, J. R.; Bligaard, T.; Jónsson, H. J. Phys. Chem. B 2004, 108, 17886-17892.

52. Neufeld, O.; Yatom, N.; Toroker, M. C. ACS Catal. 2015, 5, 7237-7243.

53. Schneider, J.; Bahnemann, D. W. J. Phys. Chem. Lett. 2013, 4, 3479-3483.

54. Juvé, V.; Crut, A.; Maioli, P.; Pellarin, M.; Broyer, M.; Del Fatti, N.; Vallée, F. Nano Lett. 2010, 10, 1853-1858.

55. Arbouet, A.; Voisin, C.; Christofilos, D.; Langot, P.; Fatti, N.D.; Vallée, F.; Lermé, J.; Celep, G.; Cottancin, E.; Gaudry, M.; Pellarin, M.; Broyer, M.; Maillard, M.; Pileni, M.P., Treguer, M. Phys. Rev. Lett. 2003, 90, 177401.

56. Jensen, S. A.; Mics, Z.; Ivanov, I.; Varol, H. S.; Turchinovich, D.; Koppens, F. H. L.; Bonn, M.; Tielrooij, K. J. Nano Lett. 2014, 14, 5839-5845. 
57. Morbec, J. M.; Narkeviciute, I.; Jaramillo, T. F.; Galli, G. Phys. Rev. B 2014, 90, 155204.

58. Nurlaela, E.; Harb, M.; del Gobbo, S.; Vashishta, M.; Takanabe, K. J. Solid State Chem. 2015, 229, 219-227.

59. Le Bahers, T.; Labat, F.; Pauporté, T.; Ciofini, I. Phys. Chem. Chem. Phys. 2010, 12, 14710-14719.
60. Le Bahers, T.; Labat, F.; Pauporté, T.; Lainé, P. P.; Ciofini, I. J. Am. Chem. Soc. 2011, 133, 8005-8013.

61. Le Bahers, T.; Pauporté, T.; Lainé, P. P.; Labat, F.; Adamo C.; Ciofini, I. J. Phys. Chem. Lett. 2013, 4, 1044-1050.

\section{$M-\mathrm{CoO}_{\mathrm{x}} / \mathrm{Ta}_{3} \mathrm{~N}_{5}$ Doped $\mathrm{CoO}_{\mathrm{x}}$}
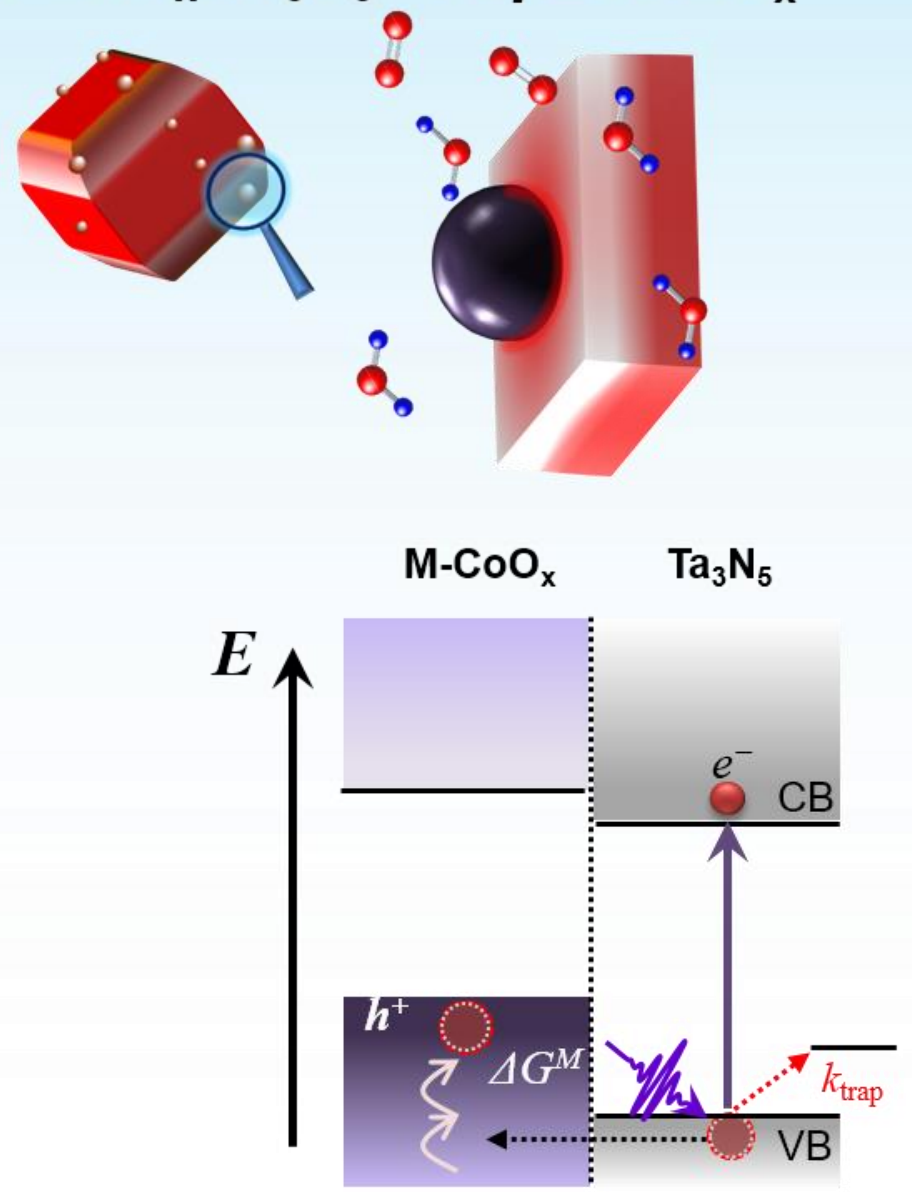

$\mathrm{CoO}_{\mathrm{x}}$

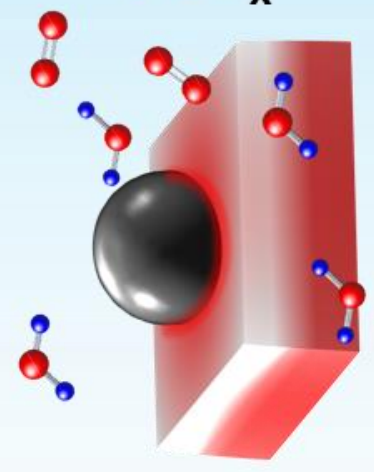

$\mathrm{CoO}_{\mathrm{x}} \quad \mathrm{Ta}_{3} \mathrm{~N}_{5}$

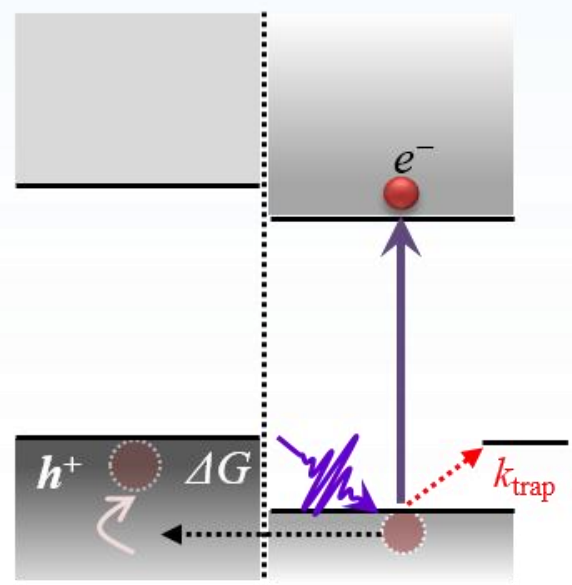

40 